\title{
Analysis of the Natural Vibration Frequency of Schwedler Reticulated Shell Structures Based on Finite Element Software
}

\author{
Mingmei, Jiang \\ Qinhuangdao Campus, Northeast Petroleum University, Qinhuangdao, 066004, China
}

\begin{abstract}
Taking a Schwedler spherical reticulated shell structure as the research object, using ANSYS finite element software, it analyzed the natural frequency and discussed the effect of self vibration frequency of the rise to span ratio, provided valuable reference for the design and analysis of this kind of shell structure.
\end{abstract}

Keywords-schwedler spherical reticulated shell; vibration frequency; the ratio of rise to span.

\section{INTRODUCTION}

Reticulated shell structure as the outstanding representative of space grid structure, has been rapidly developed and widely used in the past more than half a century. Shell has the advantages of simple structure, reasonable stress, light and elegant. The building and structure staff all use it.

Schwedler spherical reticulated shell [1] is a shell structure named by Schwedler ", the originator of reticulated shell structure. The shell surface is divided into horizontal link meridional ribs and zonal. They are all connected together. Each trapezoid grid is divided into two triangles by inclined rod. So the internal force distribution will be more uniform in the surface of the dome. The self weight of structure will be further reduced, which can span large space.

This paper takes a Schwedler spherical reticulated shell structure as the research object, using ANSYS finite element software [2], analyzed the natural frequency of the structure, discussed the effect of different rise span ratio on the vibration frequencies, and provide valuable reference for the design and analysis of this kind of shell structure.

\section{CALCULATION MODEL}

\section{A. Structure parameters}

A Schwedler spherical reticulated shell structure, which top view is circular. The diameter is $90 \mathrm{~m}$. The rise span ratio are respectively $1 / 4,1 / 6,1 / 8,1 / 10,1 / 12$. The spherical center angle is 60 degrees. The spatial three-dimensional graph, the plane projection drawing and the elevation of the structure are shown in Figure 1, figure 2 and figure 3.

The circumferential bars, radial rod and oblique rod are all made of steel pipe in the reticulated shell. The geometrical parameters of each bar are shown in table 1 .
B. The selection finite element

The ring rods in the reticulated shell are simulate by BEAM188 beam. The peripheral nodes in calculation model are articulated.

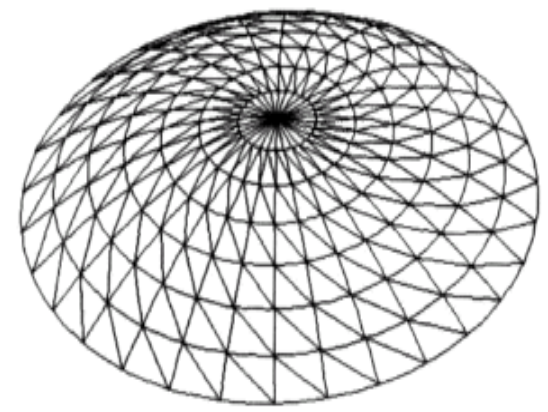

Figure 1. The spatial three-dimensional map of reticulated shells structure

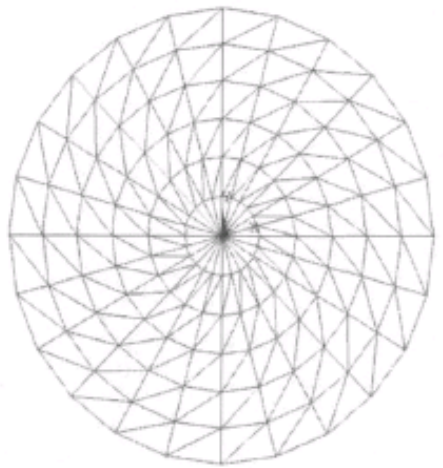

Figure 2. The plane diagram of reticulated shell structure

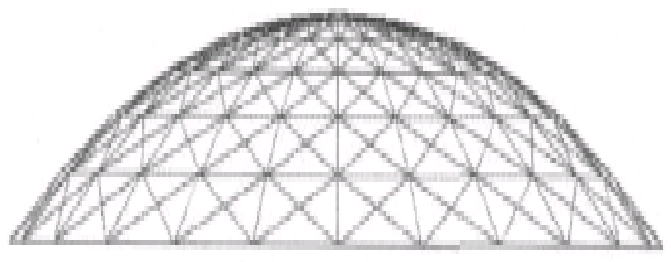

Figure 3. The elevation of reticulated shell structure 


\section{CALCULATION RESUlTS}

Through 5 different rise span ratios $(\mathrm{f} / \mathrm{L}=1 / 4,1 / 6,1 / 8$, $1 / 10,1 / 12)$ the paper analyzed self vibration frequency of the reticulated shell structure. Table 2 listed the self vibration frequency of the first 6 order under 5 different rise span ratio. Figure 4 showed the variation curve of the first order self vibration frequency with order. Figure 5 gived change curve of the first order natural frequencies under different rise span ratio $(\mathrm{L} / \mathrm{f}=4,6,8,10,12)$.

\section{CONCLUSION}

According to figure 4 , when rise span ratio is $1 / 4$ or $1 / 10$, the bulge size number is more in the order variation curve of self vibration frequency, other wise curve shape is relatively stable. With the decrease of the ratio of rise to span the first 16 order natural frequencies are almost all smaller. Figure 5 illustrates with the decrease of the rise span ratio of the shell, the first order vibration frequency decreases from slow to fast. When ratio of rise to span is from $1 / 4$ to $1 / 6$, the first order natural frequency decrease is not obvious. when rise span ratio is from $1 / 10$ to $1 / 12$, the fundamental frequency decreased quickly.

TABLE I. THE GEOMETRIC PARAMETERS OF RING ROD, DIAMETER ROD AND OBLIQUE ROD OF THE SHELL STRUCTURE

\begin{tabular}{cccccc}
\hline Rod & $\begin{array}{c}\text { Inside } \\
\text { diameter } \\
/ \mathrm{m} \mathrm{m}\end{array}$ & $\begin{array}{c}\text { outer } \\
\text { diameter } \\
/ \mathrm{m} \mathrm{m}\end{array}$ & $\begin{array}{c}\text { The } \\
\text { Poisson's } \\
\text { ratio }\end{array}$ & $\begin{array}{c}\text { shear } \\
\text { modulus } \\
/ \mathrm{MPa}\end{array}$ & $\begin{array}{c}\text { elastic } \\
\text { Modulus } \\
/ \mathrm{MPa}\end{array}$ \\
\hline $\begin{array}{c}\text { ring rod } \\
\text { diameter } \\
\text { rod } \\
\text { oblique } \\
\text { rod }\end{array}$ & 90 & 92.5 & 0.3 & 80000 & 200000 \\
\hline
\end{tabular}

TABLE II. SELF VIBRATION FREQUENCY OF THE FIRST 6 ORDER UNDER 5 DIFFERENT RISE SPAN RATIO

\begin{tabular}{cccccc}
\hline $\begin{array}{c}\text { Order } \\
\text { number }\end{array}$ & $1 / 4$ & $1 / 6$ & $1 / 8$ & $1 / 10$ & $1 / 12$ \\
\hline 1 & 3.1739 & 3.1428 & 2.9724 & 2.8458 & 2.7136 \\
2 & 4.5745 & 4.5368 & 4.1526 & 3.6912 & 3.1884 \\
3 & 5.0845 & 4.8532 & 4.3261 & 4.1906 & 4.0058 \\
4 & 5.4536 & 5.2594 & 4.9529 & 4.7821 & 4.6245 \\
5 & 5.4829 & 5.2836 & 5.0346 & 4.9169 & 4.8464 \\
6 & 6.1629 & 5.5638 & 5.4867 & 5.3652 & 5.3124 \\
\hline
\end{tabular}

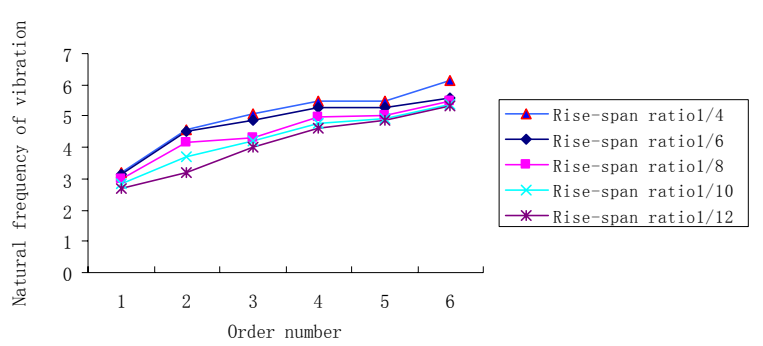

Figure 4 . The change curve of the vibration frequencies with the number of the step under 5 different rise span ratio

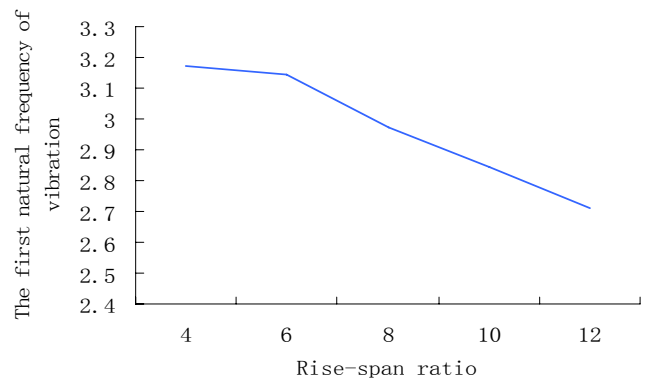

Figure 5. The change curve of the structural first order natural frequencies under 5 different rise span ratio

\section{REFERENCES}

[1] Zhang wen-Fu, Wang Xiu-Li, Spatial Structure .Beijing: Science Press, 2005

[2] Shang Xiao-Jiang, Qiu Feng, Ansys Structural Advanced Finite Element Analysis Method And Application Examples. Beijing: Chinese water conservancy and Hydropower Press, 2006 